\title{
Article
}

\section{GIS-Based Analysis and Mapping of the Winter Chilling Hours in Mainland Spain. Application to Some Sweet Cherry Cultivars}

\author{
Francisco J. Moral ${ }^{1, *(1)}$, Abelardo García-Martín ${ }^{2}$, Francisco J. Rebollo ${ }^{3}$, María A. Rozas ${ }^{2}$ and Luis L. Paniagua ${ }^{2}(0)$ \\ 1 Departamento de Expresión Gráfica, Escuela de Ingenierías Industriales, Universidad de Extremadura, Avda. \\ de Elvas, s/n., 06006 Badajoz, Spain \\ 2 Departamento de Ingeniería del Medio Agronómico y Forestal, Escuela de Ingenierías Agrarias, Universidad \\ de Extremadura, Avda. Adolfo Suárez, s/n., 06007 Badajoz, Spain; abgarcia@unex.es (A.G.-M.); \\ marozas@unex.es (M.A.R.); llpsimon@unex.es (L.L.P.) \\ 3 Departamento de Expresión Gráfica, Escuela de Ingenierías Agrarias, Universidad de Extremadura, Avda. \\ Adolfo Suárez, s/n., 06007 Badajoz, Spain; frebollo@unex.es \\ * Correspondence: fjmoral@unex.es; Tel.: +34-9-2428-9600
}

check for

updates

Citation: Moral, F.J.; García-Martín,

A.; Rebollo, F.J.; Rozas, M.A.;

Paniagua, L.L. GIS-Based Analysis

and Mapping of the Winter Chilling

Hours in Mainland Spain.

Application to Some Sweet Cherry

Cultivars. Agronomy 2021, 11, 330.

https://doi.org/10.3390/agronomy 11020330

Academic Editor: Ajit Govind

Received: 26 January 2021

Accepted: 10 February 2021

Published: 13 February 2021

Publisher's Note: MDPI stays neutral with regard to jurisdictional claims in published maps and institutional affiliations.

Copyright: (C) 2021 by the authors Licensee MDPI, Basel, Switzerland. This article is an open access article distributed under the terms and conditions of the Creative Commons Attribution (CC BY) license (https:/ / creativecommons.org/licenses/by/ $4.0 /)$.

\begin{abstract}
The knowledge of the chilling requirements for breaking rest and flowering of fruit trees is necessary to properly select cultivars and to avoid losses due to an inappropriate cultivar selection in a particular geographical location. With the aim of providing an analysis using three models (Chilling Hours, Utah Model, and Positive Utah Model) to estimate the accumulation of winter chilling, quantifying its spatial variability and representing the spatial pattern throughout mainland Spain, temperature data from 72 meteorological stations, considering the 1975-2015 period, were utilized. The statistical properties of values corresponding to each winter chilling model were assessed and, later, they were mapped by means of an integrated geographic information system (GIS) and a multivariate geostatistics (regression-kriging) and algebra map approach. The results show that measures obtained with the three chilling models were highly related, which were used to visualize the spatial variability of the accumulated winter chilling considering each model. Moreover, the fact that elevation and latitude are related to the chilling hours enables their use as auxiliary variables to better estimate at unsampled locations and generate more accurate maps. Knowledge of the spatial patterns of chill accumulation in different areas of mainland Spain is of great importance when appropriate fruit trees and cultivars have to be selected. Moreover, if a high probability of satisfying the chilling requirements in any area is considered, quantile maps can be used instead of maps based on mean values. Finally, the potential spatial distributions of three sweet cherry cultivars were delineated using the obtained maps.
\end{abstract}

Keywords: geostatistics; geographical information systems; fruit trees; chilling models

\section{Introduction}

One of the main factors influencing crop aptitude is climate [1]. Particularly, deciduous fruit trees of temperate climates require a certain amount of winter chilling to overcome their dormancy, depending on the species, cultivar, and even on the year and location [2,3]. Vegetative growth and yield are severely reduced when the accumulated chilling is lacking [4]. Fruit trees are planted in many different environmental conditions, sometimes without taking into account their chilling requirements, so incomplete breaking of dormancy occurs.

The fresh fruit producing sector is very important in Spain, both in terms of surface area, around 1,700,103 ha [5], and economic valuation, around EUR 6,600,106 [6], ranking first among countries in the European Union [7]. The wide climatic diversity of mainland Spain allows the cultivation of a great variety of fruit species, from subtropical ones, such as avocado or citrus fruits in the Mediterranean coastal areas, to fruit trees which require a temperate climate, such as olive, vine, peach, apple, etc., distributed throughout the 
Spanish territory. Cold winters and frosts occur in the interior areas of the Iberian Peninsula, making the cultivation of subtropical species impossible, but unlike these, the fruit trees of temperate climate have a dormancy period, in which they are very resistant to winter chilling, allowing for commercial cultivation.

In general, fruit trees need to accumulate between 200 and $1500 \mathrm{~h}$ below $7.22{ }^{\circ} \mathrm{C}$ during the winter to break dormancy and later to properly produce flowers and fruit $[8,9]$. The fulfillment of the chilling requirements has an important impact on the phenology of the fruit trees during the campaign, affecting their different phases and finally, the ripening process. Yong et al. [10] determined that the flowering time of some fruit trees is negatively related to the accumulated chilling hours, and Egea et al. [9], Ruiz et al. [3], and Alburquerque et al. [11] established that the chilling requirement is the most influential factor on blooming date. Additionally, the lack of chilling causes many negative effects, such as the delay and lack of sprouting uniformity, decrease in the number of flowers and vegetative buds, and fall of flowers [12]. Moreover, unusual shape of fruits and the existence of some defects (sutures and protuberances) can also be consequences of few chilling hours $[13,14]$.

There are many models which have been developed to measure the accumulation of winter chilling in fruit-growing areas. However, three of the most used models are the Chilling Hours Model, the Utah Model, and the Positive Utah Model. The Chilling Hours Model [15], also known as the Weinberger Model [16], is the oldest method to quantify winter chill that is still widely used. It considers all hours, from the start of the dormancy season, with temperatures between 0 and $7.2^{\circ} \mathrm{C}$ as equally effective for chilling accumulation.

The Utah Model [17] contains a weighting function assigning different chilling efficiencies to different temperature ranges, including negative contributions by high temperatures on winter chill accumulation. This model assigns no physiological effects to temperatures below $1.4{ }^{\circ} \mathrm{C}$, a weight of 0.5 for temperatures between 1.4 and $2.4^{\circ} \mathrm{C}$ and between 9.1 and $12.4^{\circ} \mathrm{C}$, a weight of 1 for temperatures between 2.4 and $9.1^{\circ} \mathrm{C}$ and between 12.4 and $15.9^{\circ} \mathrm{C}$, and negative weights of -0.5 for temperatures between 15.9 and $18{ }^{\circ} \mathrm{C}$ and of -1 for temperatures above $18^{\circ} \mathrm{C}$.

One modified version of the Utah Model which performs well in regions with a warm climate is the Positive Utah Model [18]. In this model, the negative contributions of warm temperatures to accumulated chilling are removed from the original equation of the Utah Model. Consequently, it assigns no physiological effects to temperatures below $1.4^{\circ} \mathrm{C}$, a weight of 0.5 for temperatures between 1.4 and $2.4{ }^{\circ} \mathrm{C}$ and between 9.1 and $12.4{ }^{\circ} \mathrm{C}$, a weight of 1 for temperatures between 2.4 and $9.1^{\circ} \mathrm{C}$, and also no physiological effects to temperatures above $12.4^{\circ} \mathrm{C}$.

Climate change has led to a decrease in the accumulation of winter chilling during recent years, particularly in areas with a Mediterranean climate $[19,20]$. In this sense, Baldocchi and Wong [8] indicated that the suitability of different cultivars will be compromised in some areas of California because of the decreasing amount of chilling hours, taking into account some future climate scenarios. Recently, Rodríguez et al. [21] reported a projected winter chill decrease for the near future over peninsular Spain and the Balearic Islands, using data from the 1976-2005 period.

Considering the aforementioned models to measure the accumulation of winter chilling, the objectives of this study were to: (1) provide a study considering the most recent years about the accumulated winter chilling throughout mainland Spain; (2) generate accurate maps of the winter chilling accumulation calculated with three different chilling models and based on a multivariate geostatistical algorithm; and (3) analyze the potential areas of Spain in which some common sweet cherry cultivars could be grown successfully.

\section{Materials and Methods}

Daily meteorological observations at 72 georeferenced weather stations (Figure 1), all of them belonging to the Meteorology Agency of the Spanish Government, were obtained. 
A period of 40 years, from 1975 to 2015, was used in this work, which is much more than the optimal length for a series (30 years) recommended by the World Meteorological Organization with the aim of obtaining reliable climate data to make predictions [22]. The raw spatial database for all weather stations contained their geographic coordinates (referenced at UTM coordinates), elevation, and daily temperature (mean, maximum, and minimum) for the period 1975-2015.

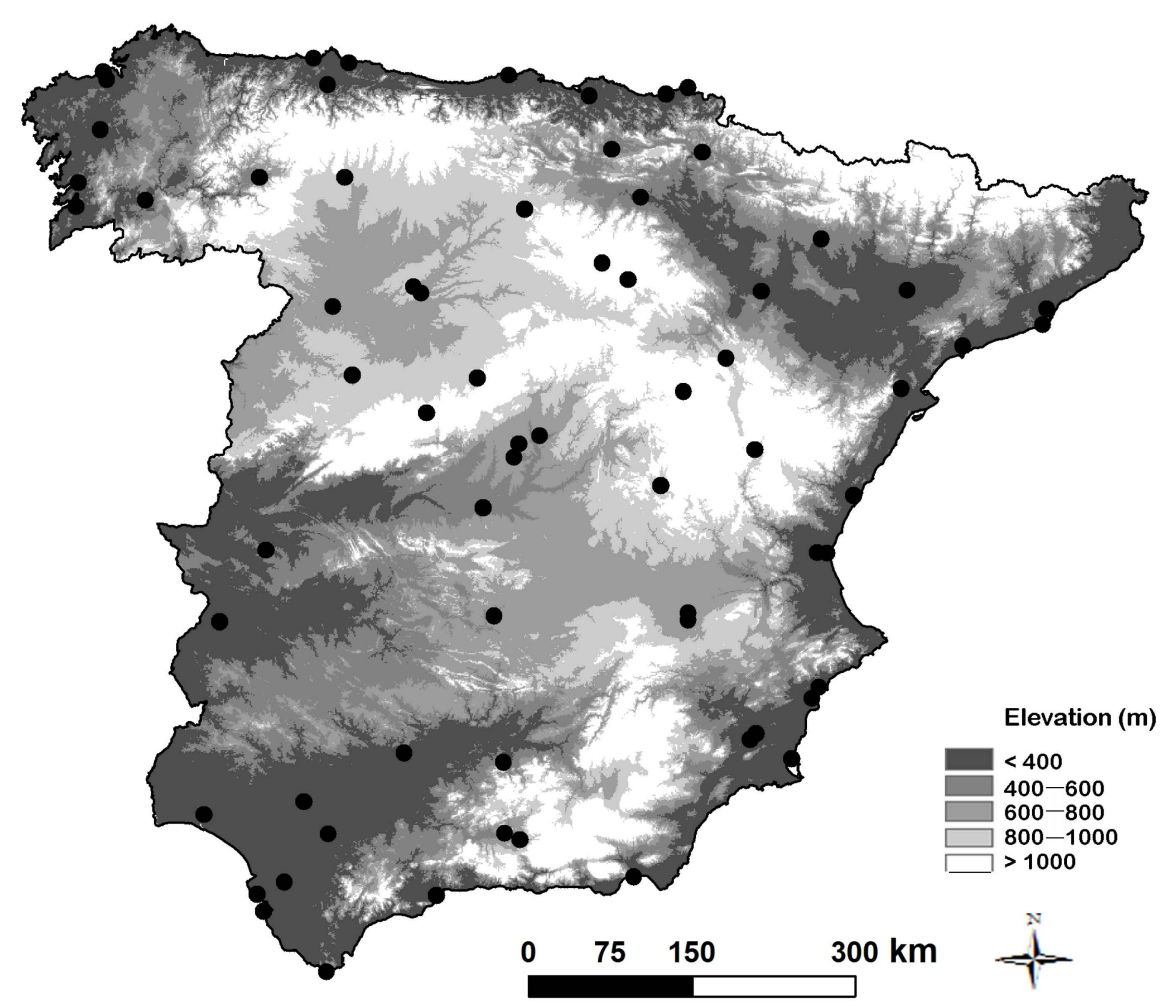

Figure 1. Digital elevation model of mainland Spain and weather stations used in this study, indicated as points.

Since chill models require hourly input data, such data were calculated from daily minimum and maximum temperatures using the methodology proposed by Baldocchi and Wong [8]. Winter chill hours were summed between November 1 and February 28. On a daily basis, the number of chill hours was computed taking into account the aforementioned constraints of each model.

Consequently, winter chill was computed using the Chilling Hours Model, the Utah Model, and the Positive Utah Model. Their units are Chilling Hours $(\mathrm{CH})$ for the Chilling Hours Model, Utah Chill Units (UCU) for the Utah Model, and Positive Chill Units (UCU+) for the Positive Utah Model. The values of these three chilling models (CH, UCU, UCU+) were incorporated in the final database together with the aforementioned initial data. Later, a geographic information system (GIS), specifically ArcGIS (version 10; ESRI, Redlands, CA, USA), was used to visualize and analyze the information.

With the aim of estimating at any location, geostatistical algorithms were used. In this section, regression-kriging (the estimator used in the case study) is briefly introduced. More information about it can be found in, for instance, Hengl et al. [23].

In regression-kriging, instead of directly estimating the considered variable $(\mathrm{CH}, \mathrm{UCU}$, and UCU+ in this study), the interpolation is performed in two steps: estimation of the trend and then kriging of residuals. These two components are added back together to give the final prediction. A simple linear regression analysis is performed in the first step between the observed value of the variable and the auxiliary variable (elevation) at all sampling locations. Later, residuals are computed as the difference between the observed or measured value of the variable and the estimate by the trend. Residuals retain the spatial 
variability of the variable and they can be estimated by ordinary kriging at any location. In consequence, any variable at a new unsampled point, $x$, is estimated, $Z_{R K}^{*}(x)$, using regression-kriging as follows:

$$
\begin{gathered}
Z_{R K}^{*}(x)=\sum_{j=0}^{p} c_{j} \cdot v_{j}(x)+\sum_{i=1}^{n} w_{i}(x) \cdot r\left(x_{i}\right) \\
v_{0}(x)=1
\end{gathered}
$$

where $c_{j}$ are the coefficients of the estimated trend model; $v_{j}(x)$ is the jth predictor at location $x$ (for $j=0$, the term represents the value where the linear regression intercepts the ordinate axis); $p$ is the number of predictors; $w_{i}(x)$, are the weights determined by solving the ordinary kriging system of the regression residuals, $r\left(x_{i}\right)$, for the $\mathrm{n}$ sample points.

More accurate estimates can be generated by a regression-kriging algorithm when the auxiliary data are available at all locations [24], as occurs with some geographical properties such as elevation, which can be extracted from a digital elevation model (DEM), in raster format at $1000 \times 1000 \mathrm{~m}^{2}$ resolution, for mainland Spain. In consequence, from data at sampling locations, i.e., weather stations, estimates at any other unsampled location can be obtained. Thus, a continuous surface over all of mainland Spain can be produced and values for each chilling model for every one of the resolution unit can be determined. Three digital models, one for each chilling index, in raster format at $1000 \times 1000 \mathrm{~m}^{2}$ resolution, were initially generated. All operations were performed in ArcGIS v.10.3 and geostatistical analysis was conducted with its extension Geostatistical Analyst.

\section{Results}

Initially, data distribution was described using some descriptive statistics (Table 1). The median and mean values were similar for the three chilling models in mainland Spain and the skewness values were low, which was indicative of data coming from a normal distribution. Moreover, the wide difference between minimum and maximum values and the high coefficients of variation for the three chilling models denote the existence of high climatic spatial variability as was expected because of the locations of the different meteorological stations (Figure 1).

Table 1. Descriptive statistics of the data for each chilling model from 1975 to 2015 and considering 72 meteorological stations in mainland Spain. SD, standard deviation; CV, coefficient of variation; $\mathrm{CH}$, Chilling hours; UCU, Utah chilling units; UCU+, Positive Utah chilling units.

\begin{tabular}{cccccccccc}
\hline & Mean & Median & SD & Min & Max & CV (\%) & Skewness & Kurtosis \\
\hline CH & 831.8 & 720.5 & 505.6 & 18.9 & 1710.3 & 60.8 & 0.1 & 1.7 \\
UCU & 1352.8 & 1530.1 & 506.2 & 20.4 & 2023.3 & 37.4 & -0.8 & 2.7 \\
UCU+ & 1384.1 & 1551.1 & 472.3 & 25.9 & 2026.1 & 34.1 & -0.8 & 2.8 \\
\hline
\end{tabular}

Table 2 shows that the values of the winter chill obtained with the three chilling models are highly correlated across Spain. A similar correlation between $\mathrm{CH}$ and UCU was obtained by Luedeling and Brown [25] in a worldwide study. The level of linearity of the different relationships and, in consequence, the level of similarity between the different chilling models is apparent, denoting that the three chilling models are functionally very similar, i.e., each model depicts similar spatial climate characteristics. As Luedeling et al. [20] indicated, deciding which model is most effective is difficult without extensive experimental model comparisons or analyses of phenological records, since the biological processes underlying the breaking of dormancy and the influence of temperature on these processes are poorly understood. Consequently, all of these chilling models are merely proxies of winter chill, relying entirely on empirical evidence. Moreover, although the mean values of the chilling models are highly correlated, with colder conditions expected in higher 
elevations, each model has a different theoretical interpretation, so they are not directly comparable.

Table 2. Correlation matrix between winter chill values, elevation, longitude, and latitude at 72 meteorological stations in mainland Spain. CH, Chilling hours; UCU, Utah chilling units; UCU+, Positive Utah chilling units.

\begin{tabular}{ccccccc}
\hline & Elevation & Latitude & Longitude & CH & UCU & UCU+ \\
\hline Elevation & 1 & & & & & \\
Latitude & 0.27 & 1 & 1 & & & \\
Longitude & -0.23 & -0.13 & 0.02 & 1 & 0.89 & 0.90 \\
CH & 0.67 & 0.66 & 0.01 & 0.89 & 1 \\
UCU & 0.52 & 0.66 & 0.02 & & & \\
UCU+ & 0.51 & &
\end{tabular}

It is also shown in Table 2 that relationships between elevation, latitude, and each chilling model are apparent, as could be expected. Alburquerque et al. [11] reported similar good correlation between UCU and elevation in Murcia, a region in southeastern Spain. In consequence, elevation and altitude seem to be the auxiliary variables used to estimate the chilling hours throughout mainland Spain using the regression-kriging algorithm. The results of the stepwise regression (ordinary least square estimation) analysis showed that the coefficient of determination was 0.41 when elevation was the unique auxiliary variable. When elevation and latitude were considered, the coefficient of multiple determination was 0.53 and the correlation was significant. The linear regression function was: $\mathrm{CH}=-2812.601+0.001 \mathrm{Y}+0.898 \mathrm{~h}$, where $\mathrm{h}$ is the elevation $(\mathrm{m})$ and $\mathrm{Y}$ is the latitude (UTM coordinate). Other auxiliary variables, such as longitude and distance to water bodies, did not significantly contribute to improve the multiple linear regression since the coefficient of multiple determination was, in any case, lower or close to 0.53.

A multivariate geostatistical work was performed to estimate $\mathrm{CH}$ at any location in Spain. The regression-kriging algorithm, in which the linear regression was the one previously indicated, used as initial data for the main variable, $\mathrm{CH}$, all values measured at each meteorological station. $\mathrm{CH}$ showed a clear spatial dependence (Figure 2); the experimental variogram was calculated and a theoretical spherical variogram was fitted to their points. Analysis of spatial correlation of residuals showed that the range of the variogram was smaller and the sill was bounded (Figure 2). This indicated that the drift had been removed. The spatial correlation structure described with the spherical variogram of residuals was integrated in the ordinary kriging algorithm to estimate $\mathrm{CH}$ residuals throughout Spain.

a)

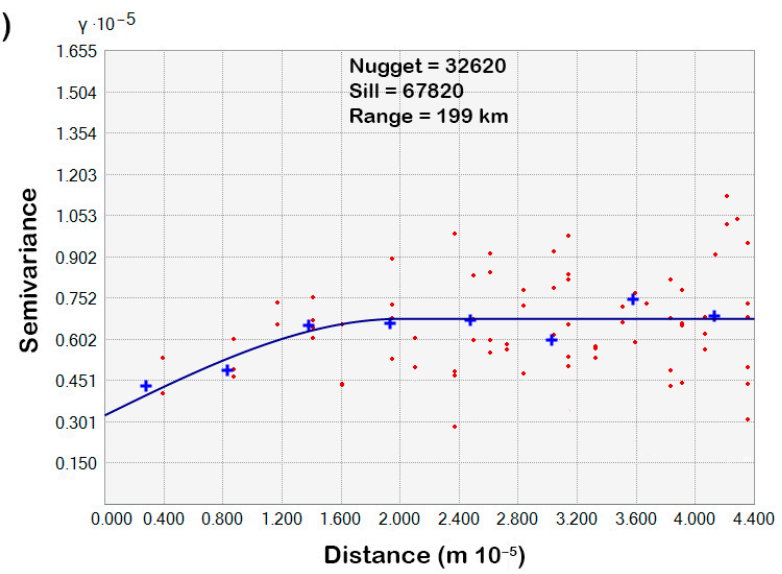

b)

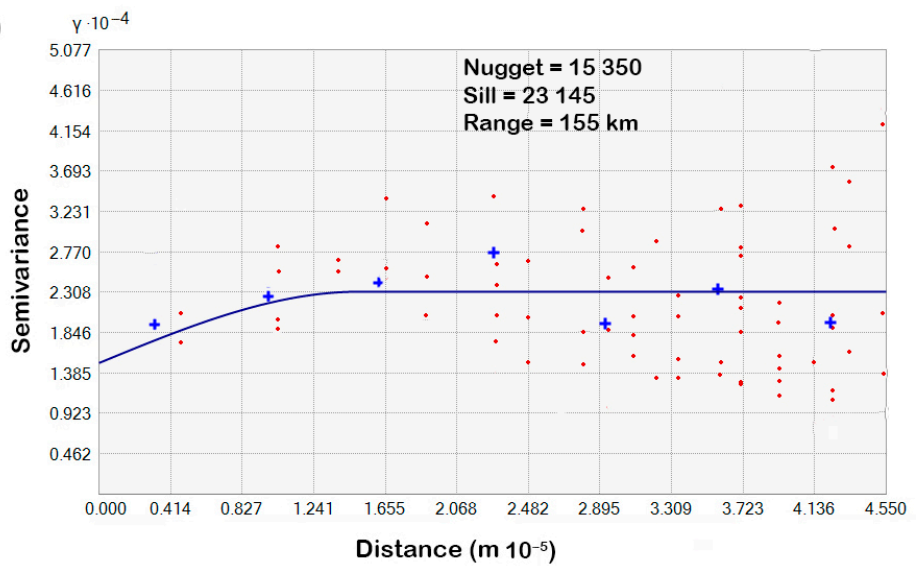

Figure 2. Digital experimental variograms (points; crosses are averaged values) and theoretical spherical variograms (lines) for the measures of winter chilling hours (a) and their residuals (b). 
The accuracy of the kriged $\mathrm{CH}$ map was determined with a cross-validation process. The mean error, which evaluated the true prediction accuracy and was computed as the difference between estimated values and actual observations at each meteorological station, was 7.62. Moreover, the root mean square error, which evaluated the accuracy of the prediction, was 79.6. As the mean $\mathrm{CH}$ value was 831.8 (Table 1), the root mean square error was lower than $9.5 \%$ of the mean value. Furthermore, when the observed $\mathrm{CH}$ values versus the predicted values were plotted, the points fell close to the 45-degree line (Figure 3). Consequently, the $\mathrm{CH}$ map represents very closely the real spatial distribution of the winter chilling hours. This is in accordance with Hengl et al. [26] who found that the accuracy of a model is higher when kriging of the residuals is incorporated in the prediction algorithm.

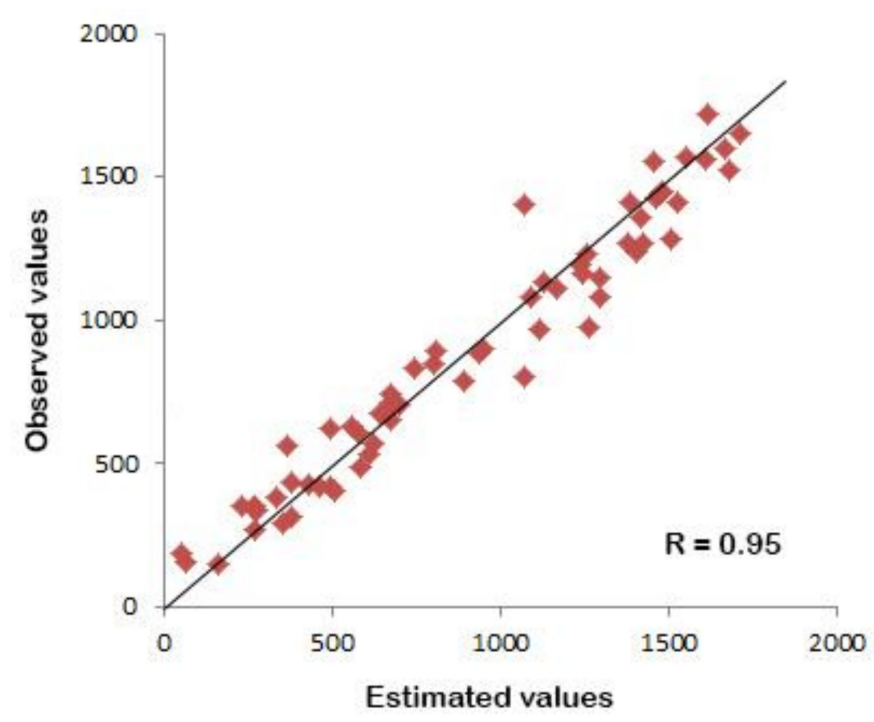

Figure 3. Observed versus predicted chilling hours at each meteorological station and correlation coefficient considering the 45-degree line.

As was shown, the RK algorithm was used to directly estimate $\mathrm{CH}$ throughout Spain. However, another alternative was checked; temperature values were also interpolated and then computed $\mathrm{CH}$. However, the mean error and the root mean square error were higher with this second alternative ( 13.87 and 257.63 , respectively). In consequence, it was less effective and this option was not considered.

Finally, the map of kriged estimates provided a visual representation of the distribution of the $\mathrm{CH}$ in Spain (Figure 4). A digital $\mathrm{CH}$ map, in raster format at $1000 \times 1000 \mathrm{~m}^{2}$ resolution, was finally generated. As correlations between $\mathrm{CH}, \mathrm{UCU}$, and $\mathrm{UCU}+$ are very high, digital maps for UCU and UCU+ throughout mainland Spain were also obtained in raster format at the same resolution $\left(1000 \times 1000 \mathrm{~m}^{2}\right)$ after applying map algebra techniques. The linear relationships considered to perform the mathematical operations are shown in Table 3. Both final digital maps for UCU and UCU+ in Spain are shown in Figure 4. 

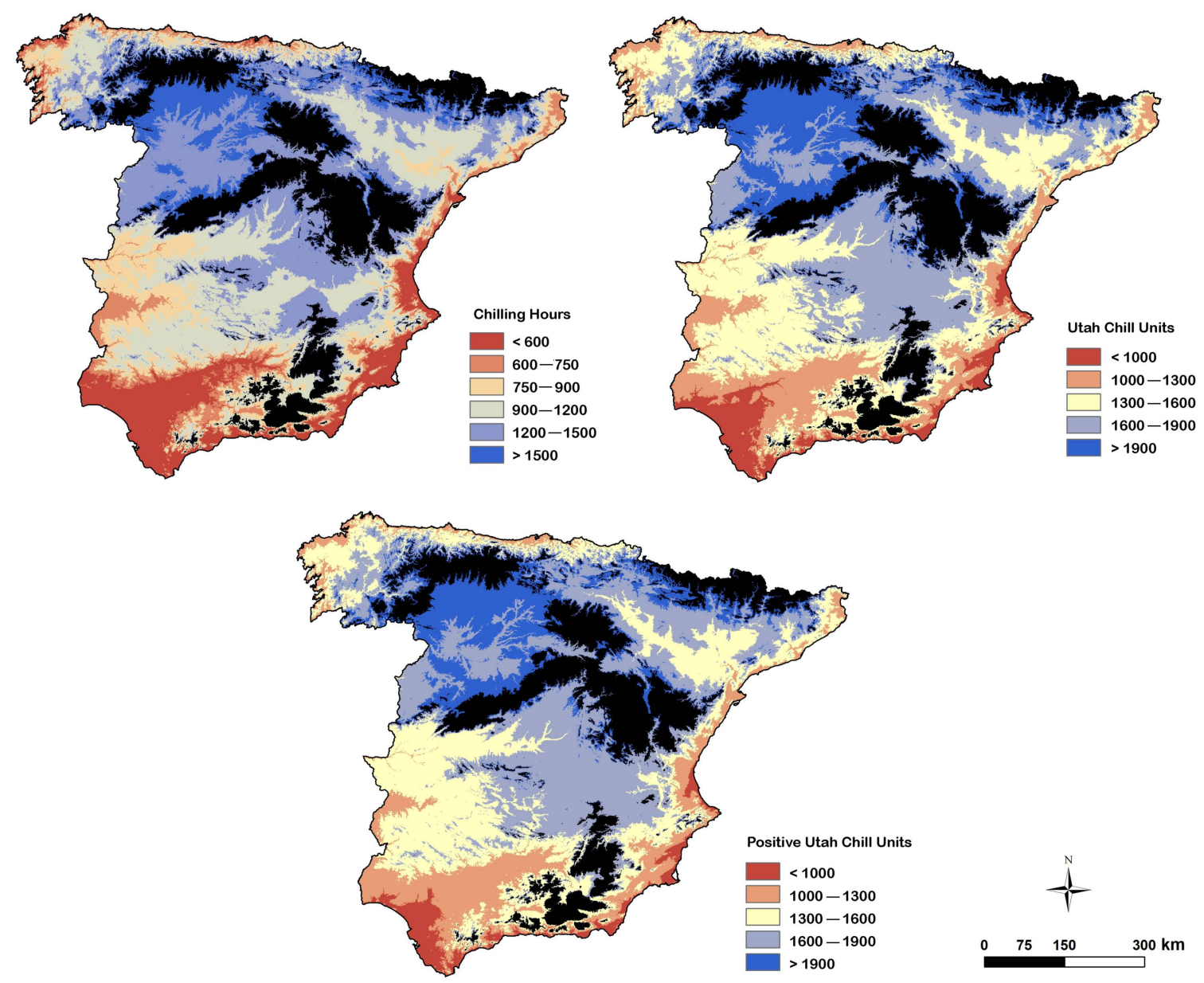

Figure 4. Observed maps of winter chill, calculated with the Chilling Hours model, the Utah model, and the Positive Utah model, for mainland Spain. Black areas are zones in which elevation is higher than $1000 \mathrm{~m}$.

Table 3. Linear relationships $(Y=a X+b)$ between Chilling Hours $(X)$ and Utah Chill Units (UCU) or Positive Utah Chill Units (UCU+) (Y).

\begin{tabular}{cccc}
\hline $\mathbf{Y}$ & $\mathbf{a}$ & $\mathbf{b}$ & $\mathbf{R}^{\mathbf{2}}$ \\
\hline UCU & 615.71 & 0.89 & 0.79 \\
UCU+ & 696.74 & 0.83 & 0.79 \\
\hline
\end{tabular}

Comparison of data at each location versus predicted values was also performed with the aim of providing an idea about the reliability of the final digital maps. Thus, it was revealed that predictions were reasonably accurate, since the correlation coefficients with respect to the straight line, $y=x$, were 0.81 and 0.82 , for UCU and UCU+, respectively.

If quantile statistics for the three chilling models are calculated, that is, winter chilling measurements are divided into intervals with equal probabilities, considering each meteorological station and the 40 annual values, and they are related to the mean values, linear regressions with high coefficients of determination are expected. In this case study, all coefficients of determination were around 0.99 , when the $25 \%$ and $75 \%$ quantiles were correlated with mean values. From the digital maps of mean values (Figure 4), new 75\% and $25 \%$ quantile maps (Figures 5 and 6) were computed by using map algebra procedures. 

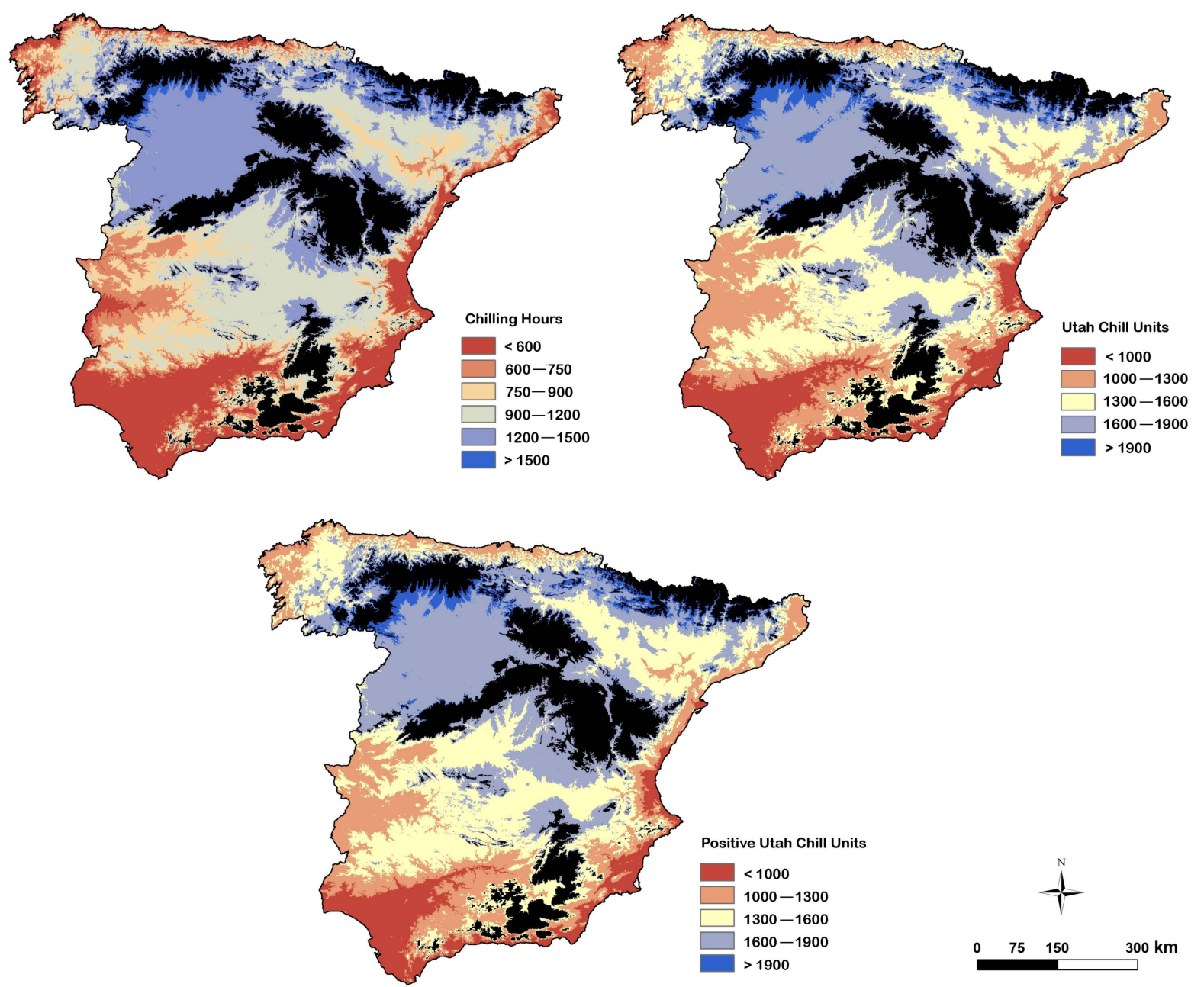

Figure 5. 75\% quantile maps of winter chill, calculated with the Chilling Hours model, the Utah model, and the Positive Utah model, for mainland Spain. Black areas are zones in which elevation is higher than $1000 \mathrm{~m}$.

Table 4 shows the percentage of the territory of mainland Spain, excluding the zones with an elevation higher than $1000 \mathrm{~m}$, within each interval defined in Figure 4. Mean $\mathrm{CH}$ are mainly in the higher intervals, above $900 \mathrm{CH}$, with more than $75 \%$ of the territory. If the quantile maps are considered, this percentage varies until around $66 \%$ and $81 \%$ for the $25 \%$ and $75 \%$ quantiles, respectively. The same was apparent when the UCU was taken into account. Mean UCU values above 1600 comprise around 59\% of the territory, and around $48 \%$ and $70 \%$ for the $25 \%$ and $75 \%$ quantile maps, respectively. For UCU+ values, the distributions were also similar, being around $60 \%$ of the territory for values above 1600 , and around $48 \%$ and $72 \%$ for the $25 \%$ and $75 \%$ quantile maps. 

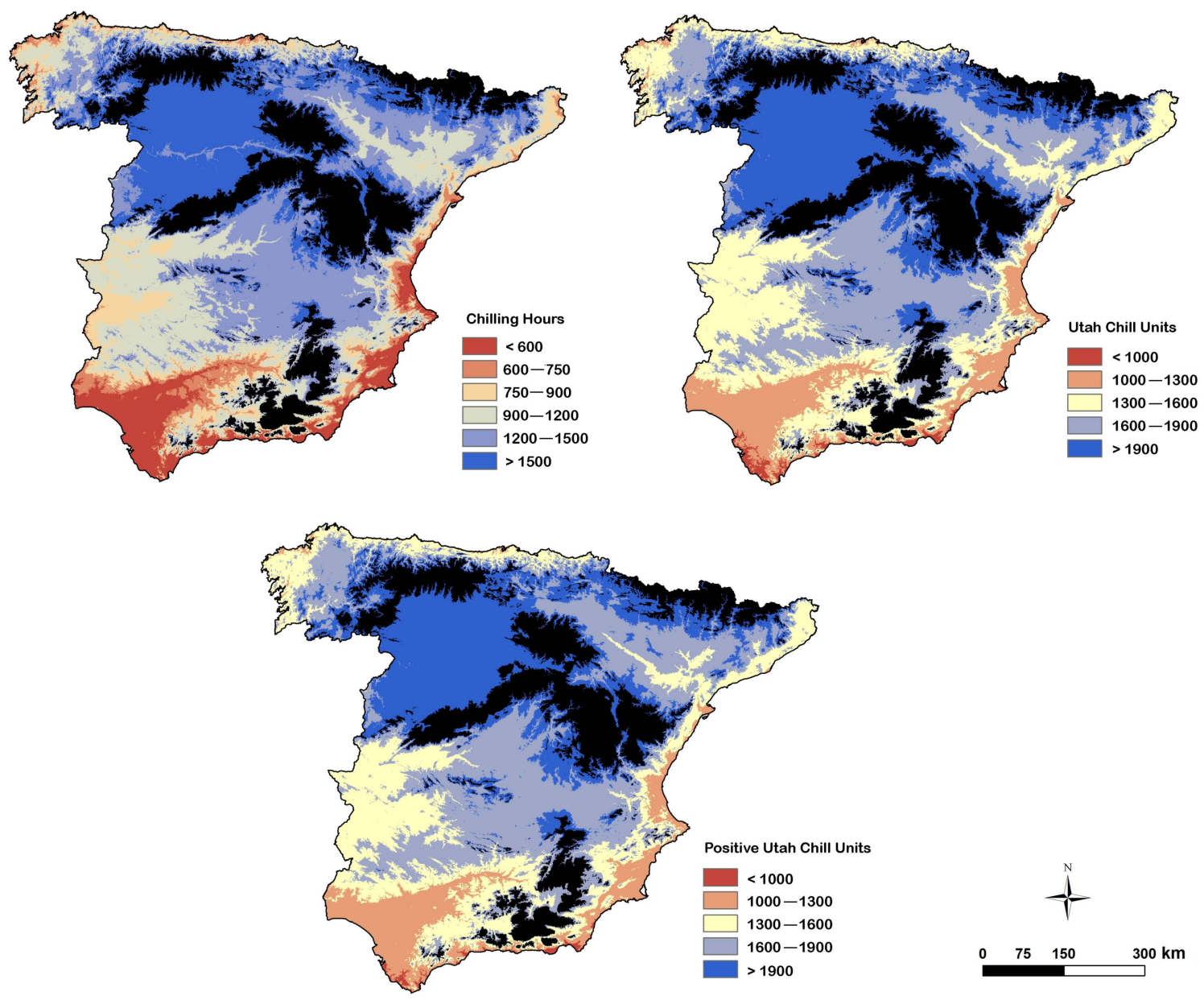

Figure 6. 25\% quantile maps of winter chill, calculated with the Chilling Hours model, the Utah model, and the Positive Utah model, for mainland Spain. Black areas are zones in which elevation is higher than $1000 \mathrm{~m}$.

Table 4. Percentage of mainland Spain within each interval for chilling hours (CH), Utah chill units (UCU), and positive Utah chill units (UCU+). Mean, 25\%, and 75\% quantiles are considered.

\begin{tabular}{cccccccccc}
\hline Interval & & CH & & & UCU & & \multicolumn{2}{c}{ UCU+ } \\
\hline & $\mathbf{2 5}$ & Mean & $\mathbf{7 5 \%}$ & $\mathbf{2 5 \%}$ & Mean & $\mathbf{7 5 \%}$ & $\mathbf{2 5 \%}$ & Mean & $\mathbf{7 5 \%}$ \\
\hline 1 & 13.5 & 8.9 & 6.0 & 8.9 & 4.3 & 0.7 & 6.8 & 2.8 & 0.3 \\
2 & 8.8 & 6.3 & 4.6 & 17.1 & 12.1 & 8.7 & 16.8 & 11.6 & 8.0 \\
3 & 10.9 & 9.4 & 7.1 & 26.4 & 24.4 & 20.0 & 28.1 & 24.8 & 19.9 \\
4 & 25.3 & 24.2 & 20.1 & 27.9 & 28.6 & 29.1 & 30.1 & 30.9 & 30.4 \\
5 & 25.7 & 25.7 & 24.2 & 19.7 & 30.6 & 41.5 & 18.2 & 29.9 & 41.4 \\
6 & 15.8 & 25.5 & 37.1 & - & - & - & - & - \\
\hline
\end{tabular}

Correspondence between the numbers and intervals are shown in Figure 2, with 1 for the lower interval and 6, for $\mathrm{CH}$, or 5, for UCU and $\mathrm{UCU}+$, for the higher interval.

\section{Discussion}

The geographic location of each area has a decisive influence on the temperature and the chill accumulation that can be recorded. Moreover, it is important to denote how the use of single climate stations to represent the climate within a region is not adequate because they cannot accurately characterize the level of spatial variability. Consequently, it is necessary to use adequate interpolation algorithms to properly perform the analysis about the spatial patterns of the studied climatic variables. Luedeling and Brown [25] compared some winter chill models for fruit and nut trees throughout the world, with 
a poor coverage in many areas worldwide. However, the resolution of the maps they provided was not sufficient to accurately delineate chilling hours at national or regional levels. For instance, the distribution of chilling hours in Spain was too general, with only two or three classes throughout its territory.

Using the multivariate geostatistical algorithm, as regression-kriging, and considering elevation and latitude as the auxiliary variables because of their good correlation with the amounts of winter chilling, the spatial distributions of $\mathrm{CH}, \mathrm{UCU}$, and UCU+ have been accurately delimited in the mainland Spain.

Growers of fruit trees in temperate climates have to select tree cultivars with the correct chilling requirements for a particular zone. Thus, for an economically viable production, cultivars of the different fruit tree species, such as, for instance, cherry, peach, plum, apple, pear, almond, or walnut, have their specific chilling requirements and, consequently, winters in the production zone must be sufficiently long and cold to satisfy the required winter chill. In this sense, the quantile maps are particularly useful tools to estimate different areas with similar accumulation of winter chill with a confidence level. For example, if a $25 \%$ quantile map is considered, areas in which the estimates are performed will have that accumulation of winter chill with a high probability during at least the $75 \%$ of the years.

Alburquerque et al. [11] analyzed the probability of satisfying the chilling requirements at different elevations for some cherry cultivars, but without showing the potential spatial distribution of them in the studied region. To illustrate the usefulness of the high-resolution digital maps to delineate and visualize the adequate areas in which different cultivars can satisfy their chilling requirements, the same particular case of some sweet cherry cultivars is utilized, since Spain is an important producing area, with around 33,000 ha [5]. The sweet cherry cultivars used in the Spanish regions are very different because of new cultivars which have been introduced from other countries and their different chilling requirements.

Considering the values of the $\mathrm{CH}$ reported by Alburquerque et al. [11] and Azizi Gannouni et al. [27], the potential spatial distribution of three cherry cultivars ("Burlat", "Marvin", and "Sunburst") growing in Spain is shown in Figure 7. The earliest flowering cultivar is "Burlat", which requires around $620 \mathrm{CH}$; the Californian cultivar "Marvin" requires around $790 \mathrm{CH}$ and "Sunburst" is a cultivar with a higher chilling requirement at around $1040 \mathrm{CH}$.

Taking into account the $\mathrm{CH}$ kriged map shown in Figure 7, obtained after considering mean $\mathrm{CH}$ values, "Burlat" could be potentially cultivated in almost every location of mainland Spain, except on the Mediterranean coast, close to the sea, and in the south, in the Guadalquivir valley and the area close to the Atlantic Ocean, where the chilling requirements would not be satisfied. Consequently, $71.2 \%$ of the total area of mainland Spain (zones higher than $1000 \mathrm{~m}$ are excluded) are potentially suitable for "Burlat". The potential spatial distribution of "Marvin" would be smaller (Figure 7); due to the high mean elevation of the Iberian Peninsula, it is around $63.4 \%$ of the Spanish territory under $1000 \mathrm{~m}$. The higher chilling requirement of "Sunburst" determines that around $45.6 \%$ of the area of Spain under $1000 \mathrm{~m}$ is potentially suitable for this cultivar, which is an important percentage of the considered territory (Figure 7). The three cultivars could be grown in this last percentage of the territory of mainland Spain, above an elevation around $460 \mathrm{~m}$, where their chilling requirements would be guaranteed. Furthermore, the wide central plateau (Meseta Central) in Spain, with a mean elevation around $660 \mathrm{~m}$, where winters are very cold, also guarantees a great number of chilling hours in a considerable area. 

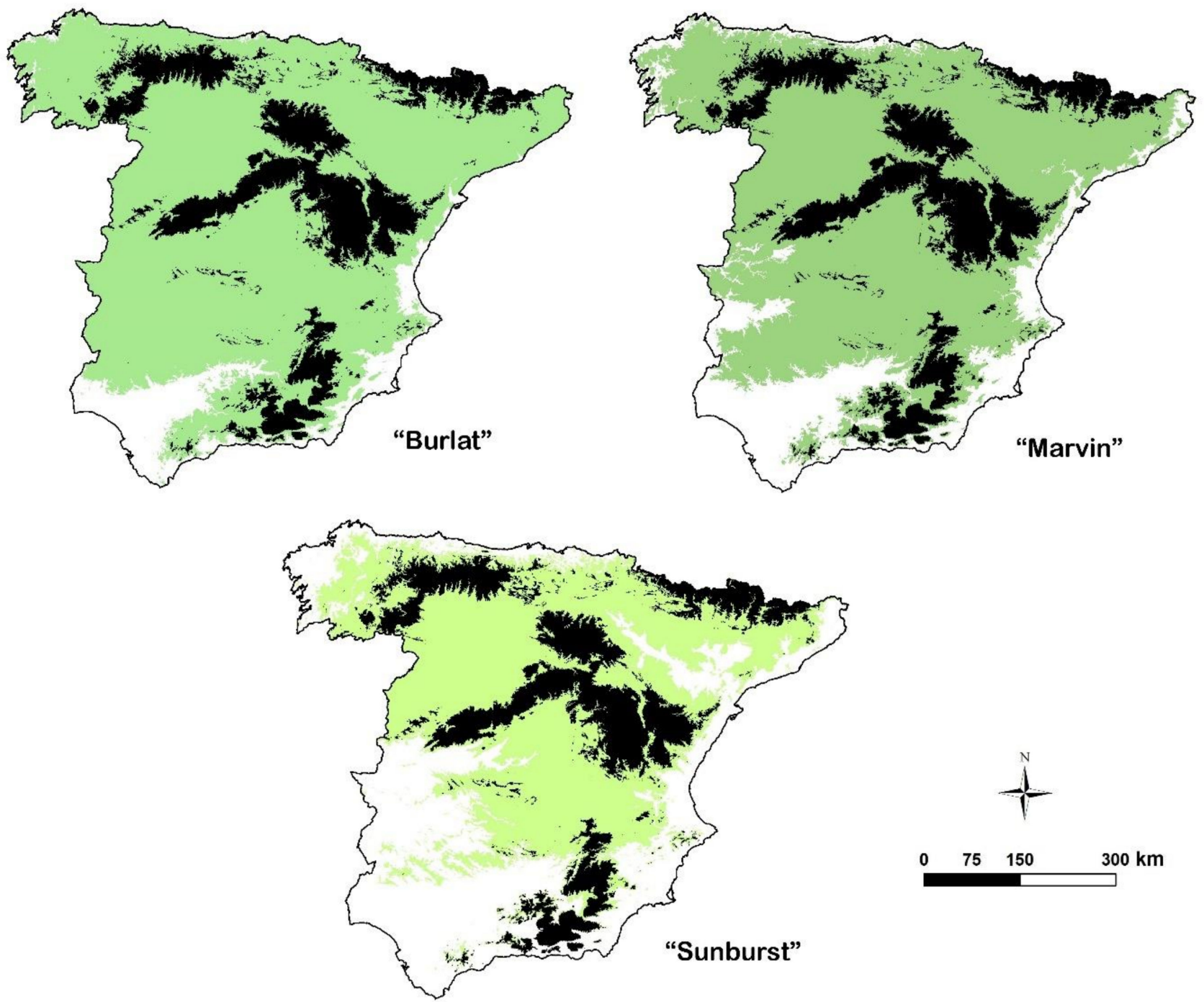

Figure 7. Potential spatial distribution of the indicated sweet cherry cultivars in mainland Spain, according to their winter chilling requirements. Black areas are zones in which elevation is higher than $1000 \mathrm{~m}$.

If a higher probability of satisfying the chilling requirements is desired, the $25 \%$ quantile map can be used to delineate the potential distribution of the sweet cherry cultivars (Figure 8), as it is likely that during $75 \%$ of the years, the requirements of winter chilling is achieved, that is, this metric defines the minimum amount of winter chill that growers can expect in $75 \%$ of all years. Thus, $66.3 \%, 55.8 \%$, and $35.5 \%$ of the total area of mainland Spain, excluding the zones higher than $1000 \mathrm{~m}$, are potentially suitable for "Burlat", "Marvin", and "Sunburst", respectively.

These maps are important tools to accurately delineate the areas in which different cultivars could be grown successfully. Particularly, those cultivars with low or medium chilling requirements are of great interest because they produce early harvests and fruit of higher quality without cracking problems, which are generated in areas with abundant rains [28]. 

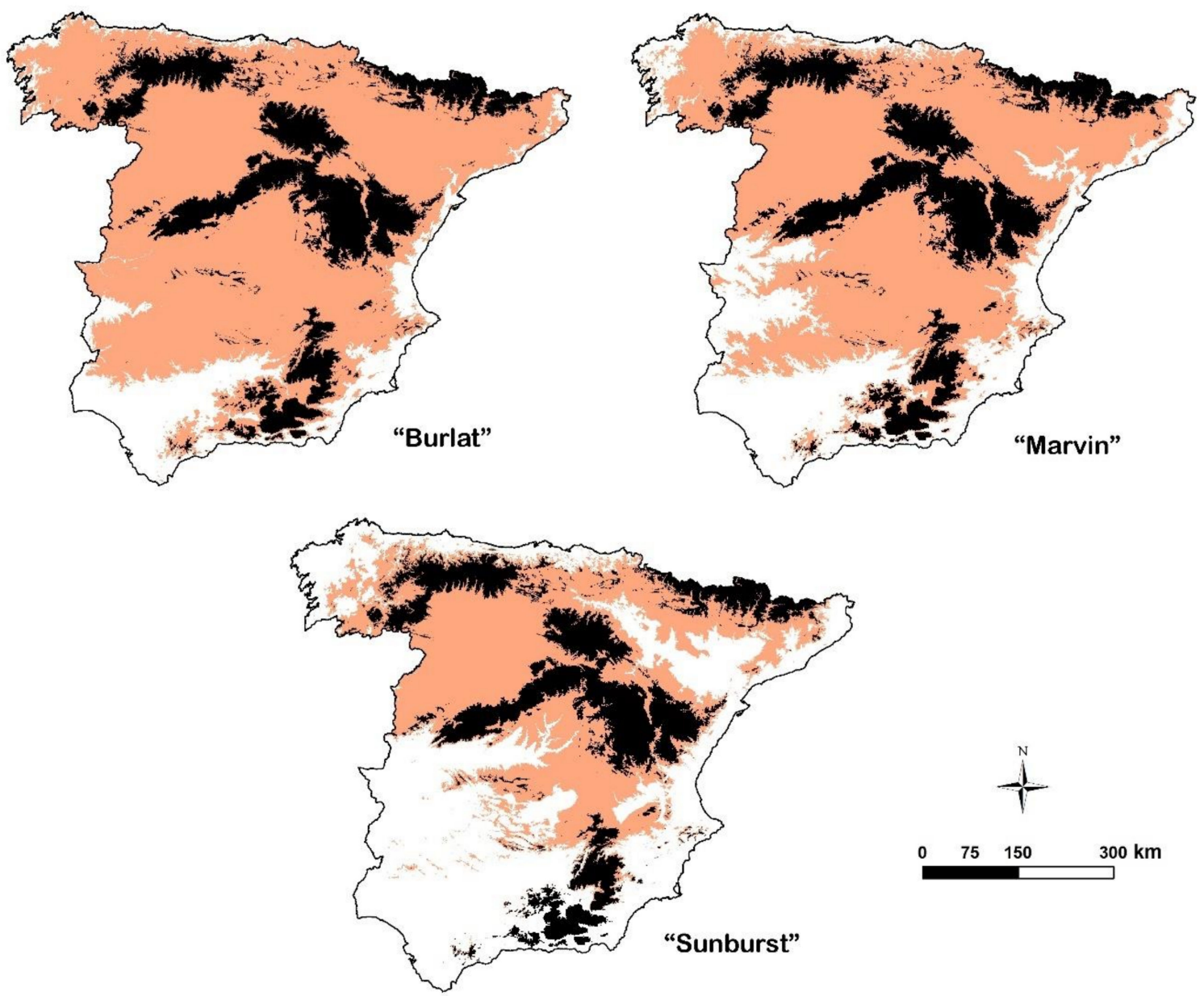

Figure 8. Potential spatial distribution of the indicated sweet cherry cultivars in mainland Spain, according to their winter chilling requirements and considering the $25 \%$ quantile maps. Black areas are zones in which elevation is higher than $1000 \mathrm{~m}$.

\section{Conclusions}

Climate information is usually related to individual stations, which is not representative of the true spatial climate patterns of a region. However, the accurate delineation of the spatial distribution of the main climate variables constitutes an important tool for decision making. In this work, the amount of winter chilling (based on three different models to measure its accumulation) throughout mainland Spain has been mapped using a GIS-based procedure.

Since accumulated chilling is mainly affected by the elevation at each location, this was utilized as an auxiliary variable to define different linear relationships between elevation and each chilling model. One of the novel aspects of this work is the use of a regressionkriging algorithm to estimate the chilling hours at any location, which could be performed by the significant linear relationships previously indicated.

Knowledge of the spatial distribution of the accumulated winter chilling is of great interest when deciding which different fruit tree species and cultivars are more suitable in a given area. Moreover, the probability of satisfying the chilling requirements can also be considered to delineate the appropriate zones.

One important characteristic of the present work is that it is based on data from the most recent time period-from 1975 to 2015. Furthermore, as far as we know, there is no similar work worldwide in which this broad and up-to-date temporal series has been used for zoning of a region or country considering the accumulation of winter chilling. 
Further work could involve the application of these maps to analyze the potential spatial distribution of the most important fruit trees and cultivars across mainland Spain, completing our knowledge of the adaptability of different species where their culture has not been traditional.

Author Contributions: Conceptualization, F.J.M., L.L.P. and A.G.-M.; methodology, F.J.M. and L.L.P.; software, F.J.R.; validation, F.J.M., L.L.P. and A.G.-M.; formal analysis, F.J.M., L.L.P. and F.J.R.; investigation, F.J.M., L.L.P., F.J.R. and A.G.-M.; resources, A.G.-M. and M.A.R.; data curation, L.L.P., A.G.-M. and M.A.R.; writing—original draft preparation, F.J.M.; writing—review and editing, F.J.M.; visualization, L.L.P. and F.J.R.; supervision, F.J.M.; project administration, L.L.P. and A.G.-M.; funding acquisition, F.J.M., L.L.P., M.A.R. and A.G.-M. All authors have read and agreed to the published version of the manuscript.

Funding: This research was funded by the Junta de Extremadura and the European Regional Development Fund (ERDF) through the projects GR18086 (Research Group TIC008), GR18088 (Research Group RNM028), and GR18011 (Research Group RNM011) and the project RTA2014-00085-00-00 financed by INIA.

Data Availability Statement: Publicy available datasets were used to compute all climate indices used in this study. These raw data can be found here: http://www.aemet.es/es/datos_abiertos. Other data obtained from this source can be available from the authors as some of them are confidential.

Conflicts of Interest: The authors declare no conflict of interest. The funders had no role in the design of the study; in the collection, analyses, or interpretation of data; in the writing of the manuscript, or in the decision to publish the results.

\section{References}

1. Rosenzweig, C.; Hillel, D. Climate Variability and the Global Harvest: Impacts of El Nino and Other Oscillations on Agro-Ecosystems; Oxford University Press: New York, NY, USA, 2008.

2. Campoy, J.; Ruiz, D.; Egea, J. Dormancy in temperate fruit trees in a global warming context: A review. Sci. Hortic. 2011, 130, 357-372. [CrossRef]

3. Ruiz, D.; Campoy, J.; Egea, J. Chilling and heat requirements of apricot cultivars for flowering. Environ. Exp. Bot. 2007, 61, 254-263. [CrossRef]

4. Erez, A. Bud Dormancy; Phenomenon, Problems and Solutions in the Tropics and Subtropics. In Temperate Fruit Crops in Warm Climates; Springer International Publishing: Berlin/Heidelberg, Germany, 2000; pp. 17-48.

5. MAGRAMA. Ministry of Agriculture, Fisheries and Food. Spanish Government. 2017. Available online: http:/ /www.mapama. gob.es/es/estadistica/temas/estadisticas-agrarias/agricultura/superficies-producciones-anuales-cultivos/ (accessed on 21 October 2020).

6. INE. Statistics National Institute. Spanish Government. Yearbook of Agrarian Statistics. 2015. Available online: http://www.ine. es/prodyser/pubweb/anuario15/anu15_12agric.pdf (accessed on 13 August 2020).

7. Eurostat. 2016. Available online: ec.europa.eu/eurostat/statistics-explained/index.php/Agricultural_production_-_crops\#Fruit (accessed on 18 October 2020).

8. Baldocchi, D.; Wong, S. Accumulated winter chill is decreasing in the fruit growing regions of California. Clim. Chang. 2008, 87, 153-166. [CrossRef]

9. Egea, J.; Ortega, E.; Martínez-Gómez, P.; Dicenta, F. Chilling and heat requirements of almond cultivars for flowering. Environ. Exp. Bot. 2003, 50, 79-85. [CrossRef]

10. Yong, L.I.; Fang, W.C.; Zhu, G.R.; Cao, K.; Chen, C.W.; Wang, X.W.; Wang, L.R. Accumulated chilling hours during endo-dormancy impact blooming and fruit shape development in peach (Prunus persica). J. Integr. Agric. 2016, 15, 1267-1274.

11. Alburquerque, N.; García-Montiel, F.; Carrillo, A.; Burgos, L. Chilling and heat requirements of sweet cherry cultivars and the relationship between altitude and the probability of satisfying the chill requirements. Environ. Exp. Bot. 2008, 64, 162-170. [CrossRef]

12. Agustí, M. Fruticultura; Ediciones Mundi-Prensa: Madrid, Spain, 2010.

13. Sherman, W.; Beckman, T. Climatic adaptation in fruit crops. Acta Hortic. 2003, 622, 411-428. [CrossRef]

14. Wert, T.W.; Williamson, J.G.; Chaparro, J.X.; Miller, E.P.; Rouse, R.E. The Influence of Climate on Fruit Shape of Four Low-chill Peach Cultivars. HortScience 2007, 42, 1589-1591. [CrossRef]

15. Chandler, W.H. Deciduous Orchards; Lea \& Febiger: Philadelphia, PA, USA, 1942.

16. Weinberger, J.H. Chilling requirements of peach varieties. Proc. Am. Soc. Hortic. Sci. 1950, 56, 122-128.

17. Richardson, E.A.; Seeley, S.D.; Walker, D.R. A model for estimating the completion of rest for Redhaven and Elberta peach trees. Hortscience 1974, 9, 331-332. 
18. Linsley-Noakes, G.; Allan, P. Comparison of two models for the prediction of rest completion in peaches. Sci. Hortic. 1994, 59, 107-113. [CrossRef]

19. Luedeling, E.; Zhang, M.; Girvetz, E.H. Future winter chill for fruit and nut trees in California during 1950-2099. PLoS ONE 2009, 4, e6166. [CrossRef] [PubMed]

20. Luedeling, E.; Zhang, M.; Luedeling, V.; Girvetz, E.H. Sensitivity of winter chill models for fruit and nut trees to climatic changes expected in California's Central Valley. Agric. Ecosyst. Environ. 2009, 133, 23-31. [CrossRef]

21. Rodríguez, A.; Pérez-López, D.; Sánchez, E.; Centeno, A.; Gómara, I.; Dosio, A.; Ruiz-Ramos, M. Chilling accumulation in fruit trees in Spain under climate change. Nat. Hazards Earth Syst. Sci. 2019, 19, 1087-1103. [CrossRef]

22. World Meteorological Organization. Guide to Climatological Practices; World Meteorological Organization: Geneva, Switzerland, 2011.

23. Hengl, T.; Heuvelink, G.B.M.; Rossiter, D.G. About regression-kriging: From equations to case studies. Comput. Geosci. 2007, 33, 1301-1315. [CrossRef]

24. Moral, F.J. Comparison of different geostatistical approaches to map climate variables: Application to precipitation. Int. J. Clim. 2009, 30, 620-631. [CrossRef]

25. Luedeling, E.; Brown, P.H. A global analysis of the comparability of winter chill models for fruit and nut trees. Int. J. Biometeorol. 2010, 55, 411-421. [CrossRef] [PubMed]

26. Hengl, T.; Heuvelink, G.B.; Stein, A. A generic framework for spatial prediction of soil variables based on regression-kriging Geoderma 2004, 120, 75-93. [CrossRef]

27. Gannouni, T.A.; Campoy-Corbalan, J.A.; Quero-García, J.; Barreneche, T.; Arif, A.; Albouchi, A.; Ammari, Y. Dormancy related traits and adaptation of sweet cherry in Northern Africa: A case of study in two Tunisian areas. Sci. Hortic. 2017, 219, 272-279. [CrossRef]

28. Caprio, J.M.; Quamme, H.A. Influence of weather on apricot, peach and sweet cherry production in the Okanagan Valley of British Columbia. Can. J. Plant Sci. 2006, 86, 259-267. [CrossRef] 